\title{
Impact of Out-of-Pocket Costs on Prescription Fills Among New Initiators of Biologic Therapies for Rheumatoid Arthritis
}

\author{
Sari Hopson, MSPH, PhD; Kim Saverno, PhD; Larry Z. Liu, MD, PhD; Ahmad AL-Sabbagh, MD; \\ John Orazem, PhD; Mary E. Costantino, PhD; and Margaret K. Pasquale, PhD
}

\begin{abstract}
BACKGROUND: Biologic disease-modifying antirheumatic drug (DMARD) therapies are a mainstay of treatment for rheumatoid arthritis (RA), yet high member out-of-pocket (0OP) costs for such therapies may limit patient access to these therapies.
\end{abstract}

OBJECTIVE: To understand whether there is a relationship between 00P costs and the initial fill and subsequent refills of biologic DMARD treatments for RA members.

METHODS: Members of a national Medicare Advantage and Prescription Drug (MAPD) plan with an adjudicated (paid or reversed) claim for a biologic DMARD indicated for RA were identified from July 1, 2007, to December 31,2012 , and followed retrospectively. The first adjudicated claim date was the index date. Members were required to have 180 days of continuous enrollment pre- and post-index and $\geq 1$ diagnosis for RA (ICD-9-CM: 714.0 or 714.2) during pre-index or $\leq 30$ days post-index. Low-income subsidy and Medicaid-Medicare dual-eligible patients were excluded. The analysis used multivariate regression models to examine associations between initial prescription (Rx) abandonment rates and 00P costs and factors influencing the refill of a biologic DMARD therapy based on pharmacy claims.

RESULTS: The final sample size included 864 MAPD members with an adjudicated claim for a biologic DMARD. The majority were female (77.4\%) and mean age was 63.5 years $(S D=10.9)$. Most $(78 \%)$ had conventional nonbiologic DMARD utilization during pre-index. The overall initial abandonment rate was $18.2 \%$ for biologic DMARDs, ranging from $1.3 \%$ for the lowest 00P cost group (\$0-\$250) to $32.7 \%$ for the highest 00P cost group ( $>\$ 550 ; P<0.0001$ for Cochran-Armitage trend test). ORs for abandonment rose from 18.4 to 32.7 to 41.2 for 00P costs of $\$ 250.01-\$ 400.00$, $\$ 400.01-\$ 550.00$, and $>\$ 550.00$ respectively, relative to 00P costs of $\leq \$ 250.00$ (all $P<0.0001$ ). Meeting the catastrophic coverage limit and utilization of a specialty pharmacy for the index claim were both associated with a decreased likelihood of abandoning therapy $(O R=0.29$ and $O R=0.14$, respectively; both $P<0.05)$. Among the subset of 533 members with a paid claim, $82.4 \%$ had at least 1 refill post-index. The negative association between 00P cost and likelihood of refilling an Rx was highly significant $(P<0.0001)$.

CONCLUSIONS: This study suggests that the higher the member 00P cost, the less likely an MAPD member is to initiate or refill a biologic DMARD therapy for RA. Further research is needed to understand reasons for initial Rx abandonment and lack of refills, including benefit design and adverse events.

J Manag Care Spec Pharm. 2016;22(2):122-30

Copyright $\odot 2016$, Academy of Managed Care Pharmacy. All rights reserved.

\section{What is already known about this subject}

Biologic disease-modifying antirheumatic drug (DMARD) therapies are a mainstay of treatment for rheumatoid arthritis, yet high member out-of-pocket (OOP) costs for such therapies may limit member access to these therapies.

Prior research has indicated a negative relationship between member OOP costs and adherence to specialty medications.

\section{What this study adds}

OOP costs significantly affected whether a biologic DMARD therapy would be initiated or maintained. For the members with a Medicare Advantage and Prescription Drug plan, the lower the OOP cost, the more likely the member would remain adherent, while the higher the OOP cost, the less likely a member was to initiate therapy or follow through with refilling a prescription.

The finding of increased abandonment as OOP costs rose was tempered by the fact that reaching the catastrophic coverage threshold was associated with reduced abandonment.

Use of a specialty pharmacy was associated with reduced abandonment rates.

T reatment for rheumatoid arthritis (RA), a difficult, painful disease to bear, has changed significantly in the past 10 years with the development and use of biologic disease-modifying antirheumatic drug therapies (DMARDs). These include abatacept, adalimumab, certolizumab pegol, etanercept, infliximab, and rituximab and range in mode of administration from subcutaneous injection to intravenous injection. Biologic DMARDs are specialty drugs developed by pharmaceutical companies that often require special handling and administration, such as patient self-injection or physician administration. ${ }^{1}$

Biologic DMARD therapies are a mainstay of moderate to severe RA treatment, yet their high out-of-pocket (OOP) costs may limit many patients' access to these effective therapies. ${ }^{2}$ While insurers often cover such therapies, they also often require cost-sharing in the form of coinsurance or copayment for health services. However, research has shown that cost-sharing can have negative unintended consequences, such as decreased use of crucial medications and increased use of medical services. ${ }^{3-5}$ Prior research has indicated a negative relationship between member OOP costs and medication 


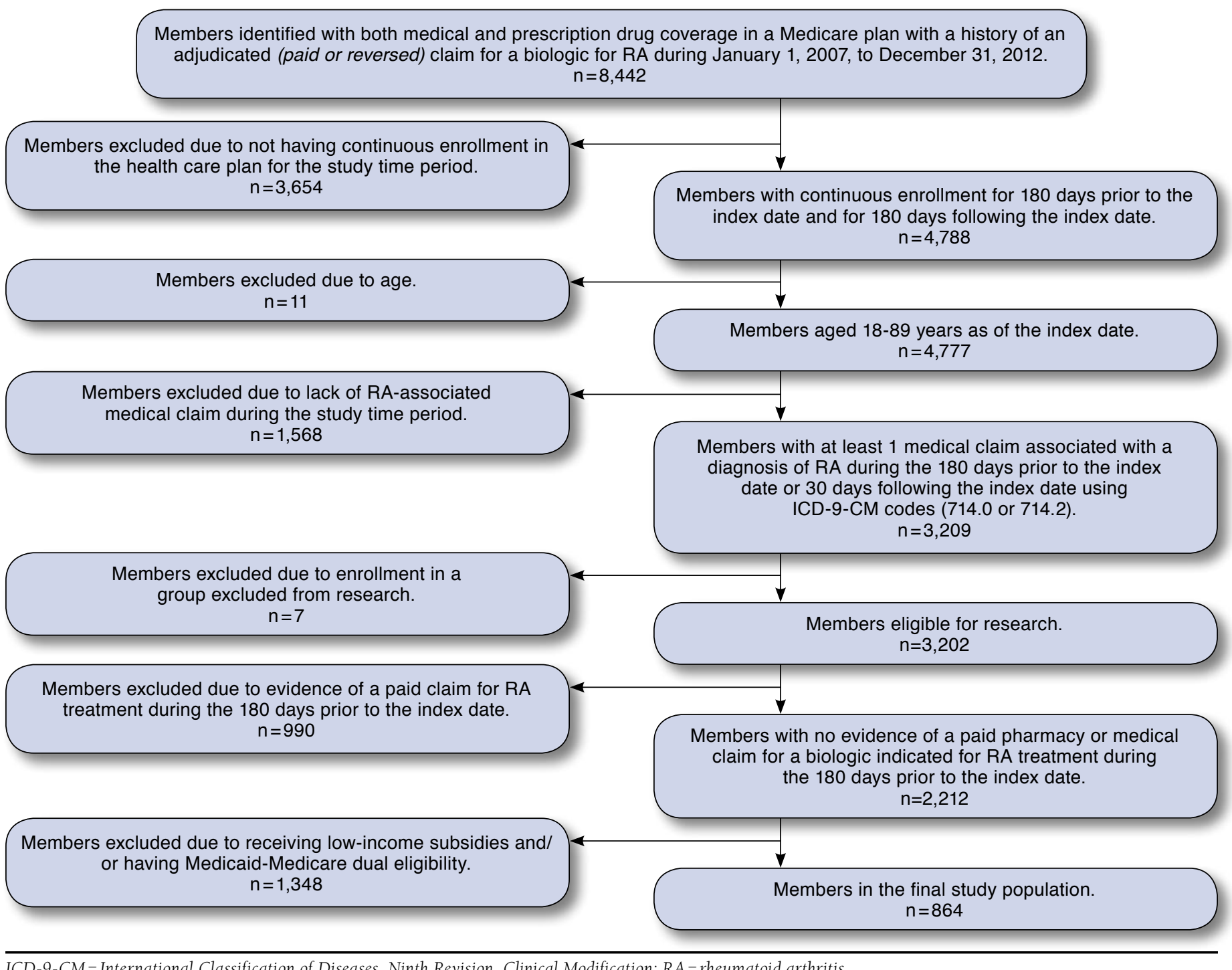

ICD-9-CM= International Classification of Diseases, Ninth Revision, Clinical Modification; RA=rheumatoid arthritis.

adherence to specialty medications. ${ }^{3,6}$ In fact, the American College of Rheumatology recognized that high OOP costs can be a barrier to the use of biologic DMARDs in its 2008 guidelines for the management of RA. ${ }^{7}$

Biologic DMARDs used to treat RA come at high and varied OOP costs. ${ }^{8,9}$ For example, recent reviews reported that costs per member for yearly direct medical expenses for members with RA ranged from $\$ 2,000$ to $\$ 10,000$, with indirect costs varying from $\$ 1,500$ to $\$ 22,000$ per member. ${ }^{10-12}$ This wide range of price is dependent on several variables, including the economic and statistical models used by each study to assess cost and the treatment regimen prescribed by the physician, among others.
Treatment adherence by the member can be the mitigating factor in controlling and alleviating the symptoms of RA, and the cost burden to the member has been shown to have a direct impact on follow-through, and consequently efficacy, of treatment for RA members prescribed biologic DMARD therapy. ${ }^{3,8}$ A study by Gleason et al. (2009) $)^{3}$ showed that a member with OOP expenses greater than $\$ 100$ for tumor necrosis factor inhibitors among biologic DMARD therapies was associated with greater risk for prescription $(\mathrm{Rx})$ abandonment (OOP \$0-\$100, 4.7\% abandonment; OOP > \$100, 10.5\%-26.4\% abandonment; $P<0.001)$. Furthermore, Karaca-Mandic et al. $(2010)^{8}$ demonstrated the level of coverage provided by the 


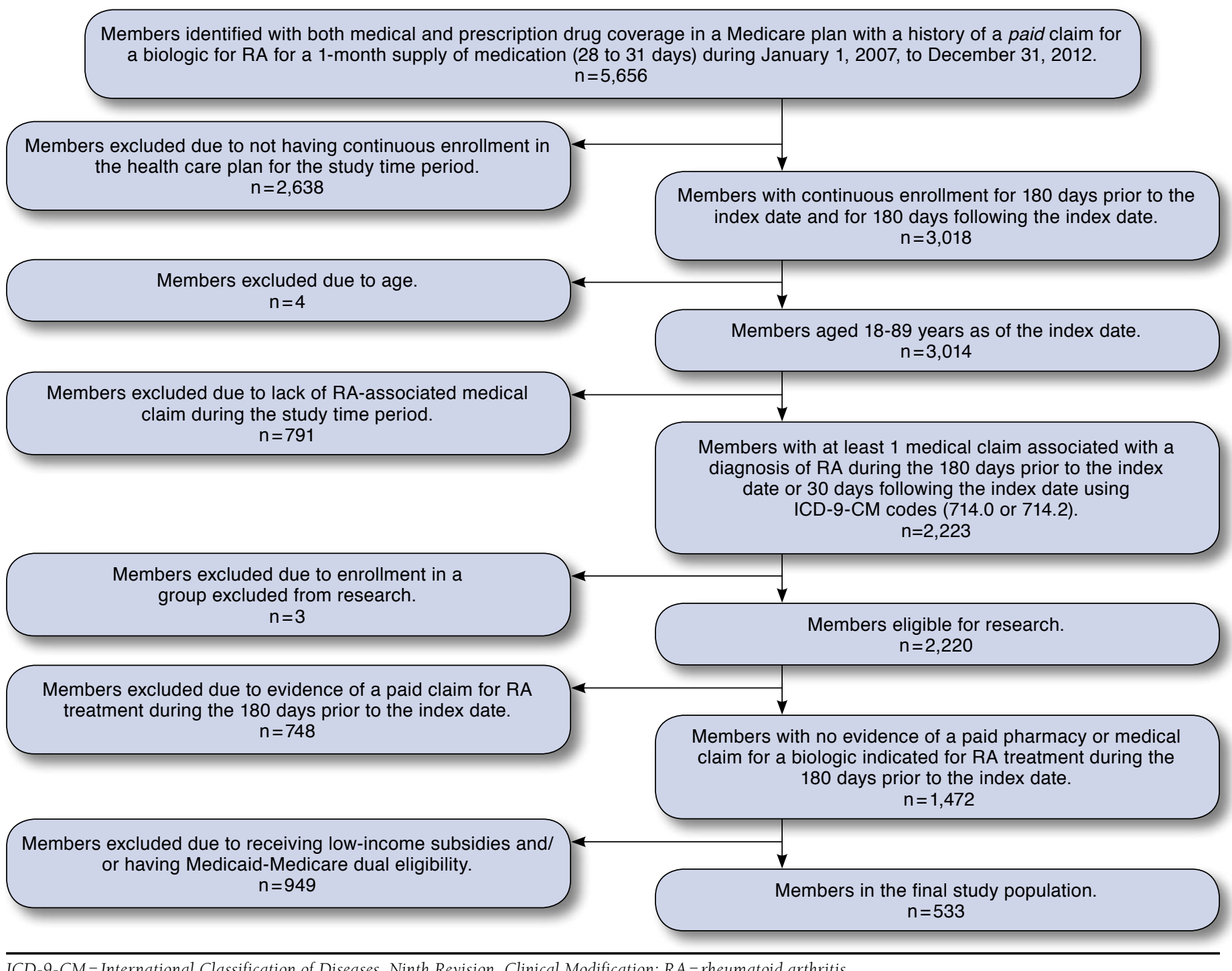

ICD-9-CM = International Classification of Diseases, Ninth Revision, Clinical Modification; RA=rheumatoid arthritis.

insurer and the member's household economics directly affected the probability that members with RA would start and continue their therapy. Interestingly, in a systematic review, the 2 most important factors identified in RA member adherence were the relationship between the provider and the member and the belief in the necessity of the medication..$^{13}$

For individuals with RA, adherence to therapy is paramount to consistent pain relief. The factors that can affect adherence should be examined and used to help form policies that can maximize follow-through for members filling RA-related Rxs. This study examined the association between Rx abandonment rates of biologic DMARD therapies and OOP costs for RA mem- bers with Medicare coverage and the factors associated with the likelihood of refilling a biologic therapy. In addition, the impact of reaching the catastrophic coverage threshold and use of specialty pharmacy were both examined within the context of OOP costs and abandonment rates.

\section{Methods}

This study utilized data from Humana, a large national health insurance provider. The Humana Research Database contains enrollment, medical, and pharmacy claims for Humana's Medicare and fully insured commercial members. All data sources were merged using deidentified patient data. The 


\section{FIGURE 3 Rate of Prescription Abandonment by} Out-of-Pocket Cost

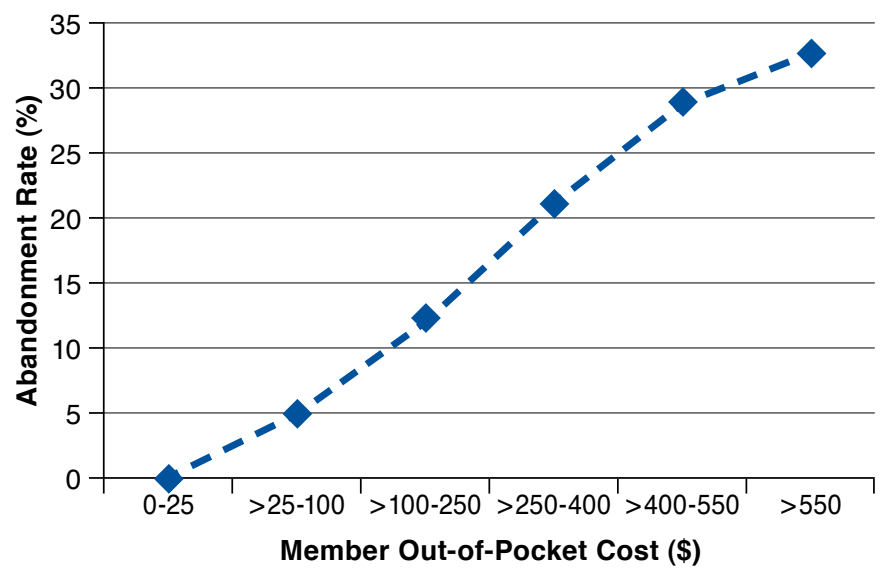

finalized protocol was approved by an independent institutional review board.

This study was a retrospective cohort analysis of all Medicare Advantage members in Humana's database identified as having an adjudicated claim for a biologic DMARD indicated for the treatment of RA between July 1, 2007, and December 31, 2012. Two distinct populations were analyzed in this study. The first population (Figure 1) was used to assess Rx abandonment rates where the date of the initial claim (paid or reversed) was considered the index date. An abandoned claim was defined as a reversed claim for a biologic DMARD medication without evidence of a subsequent paid claim for the biologic DMARD medication in the 180-day period following the initial reversed claim. For members with a reversal and a subsequent paid claim in the 180-day period following the initial reversal, this index date was reassigned to the date of the first paid claim. The second population (Figure 2) was used to assess Rx refill behavior among members with a paid claim for a biologic DMARD medication where the index date was assigned to the first paid claim for a months supply (28 to 31 days supply) of a biologic DMARD indicated for the treatment of RA. Biologic DMARD refill behavior was recorded over the 180-day post-index period. A refill was defined as a fill for any biologic DMARD indicated for the treatment of RA during the 180-day post-index period (i.e., the refill biologic DMARD may be different from the biologic DMARD indicated on the index date). For both analyses, members were followed from their index date until they were lost to follow-up due to death, loss of eligibility, or the end of the study period (June 30, 2013).

Members aged 18 to 89 years selected for the study were required to be continuously enrolled in the Medicare Advantage and Prescription Drug (MAPD) plan for 180 days before the index date and 180 days following the index date. In addition, patients were required to have an International Classification of Diseases, Ninth Revision, Clinical Modification (ICD-9-CM) primary diagnosis code of 714.0 or 714.2 in the 180-day preperiod or within 30 days following the index date. Those with at least 1 paid pharmacy or medical claim for a biologic indicated for the treatment of RA in the 180-day period prior to the index date were excluded from the analysis. Because there is a lag between the time of initial Food and Drug Administration (FDA) approval of a medication and assignment of a unique Healthcare Common Procedure Coding System (HCPCS) code for a medication, HCPCS codes J3490, "unclassified drug," and J3590, "unclassified biologic," were also utilized in combination with a minimum paid claim amount of $\$ 500$ to identify potential users of biologic DMARDs during the 180-day pre-period for the purposes of excluding patients with prior biologic utilization. Members with at least 1 paid pharmacy or medical claim for a biologic DMARD indicated for the treatment of RA or HCPCS codes J3490 or J3590 with a minimum paid claim amount of $\$ 500$ in the 180 -day period prior to the index date were excluded from analysis. Additionally, members enrolled in the Medicare low-income subsidy (LIS) program and/or who were eligible for both Medicaid and Medicare coverage were removed from the study population.

Demographic characteristics were summarized for the target population, including age, gender, and geographic location. For each of the adjudicated claims, the OOP cost was captured, and members were stratified according to OOP cost. Defining the levels for stratifying OOP cost did not occur until data analysis in order to achieve balance between relatively even dollar intervals and sufficient sample sizes within the dollar intervals.

A preliminary univariate trend test was calculated to determine whether the OOP cost was associated with the likelihood of abandoning an Rx for a biologic DMARD used to treat RA among initial users of such therapies. Multivariate logistic regression models were then used to test for an association between OOP cost and rate of prescription abandonment after adjusting for age; gender; pharmacy type (retail/specialty or other) associated with index claim; specific biologic DMARD associated with index claim; race/ethnicity; history of conventional nonbiologic DMARD use; history of nonsteroidal anti-inflammatory drug (NSAID) use; urban/rural residence; prescriber specialty associated with index claim; OOP health care costs incurred during the 180-day pre-period; ZIP code level median household income; ZIP code population percentage with high school diploma as highest attained level of education using ZIP code-level census data; the Deyo-Charlson Comorbidity Index (DCI) calculated from medical claims during the 180-day pre-period; and whether the member had reached their catastrophic coverage limit $(\mathrm{Y} / \mathrm{N})$. Goodness of fit was measured using the Hosmer-Lemeshow test.

For behavior related to refilling prescriptions, a generalized linear model with a logit link and binomial distribution was 
Impact of Out-of-Pocket Costs on Prescription Fills Among New Initiators of Biologic Therapies for Rheumatoid Arthritis

TABLE 1 Characteristics of MAPD Members with Rheumatoid Arthritis Who Attempted to Initiate Therapy with a Biologic ${ }^{a}$

\begin{tabular}{|c|c|c|c|c|c|c|c|c|c|}
\hline Cost Groups & $\begin{array}{c}\text { Member } \\
\mathbf{n}\end{array}$ & $\begin{array}{c}\text { Members with } \\
\text { Abandoned } \\
\text { Rx } \\
\text { n (\%) }\end{array}$ & $\begin{array}{l}\text { Mean Age } \\
\text { (SD) }\end{array}$ & $\begin{array}{l}\text { Males } \\
\text { n (\%) }\end{array}$ & $\begin{array}{l}\text { Pre-period } \\
\text { DMARD } \\
\text { Utilization } \\
\text { n (\%) }\end{array}$ & $\begin{array}{l}\text { Pre-period } \\
\text { NSAID } \\
\text { Utilization } \\
\text { n (\%) }\end{array}$ & $\begin{array}{l}\text { Urban } \\
\text { Residence } \\
\text { n (\%) }\end{array}$ & $\begin{array}{l}\text { Median Pre-period } \\
\text { OOP Health Care } \\
\text { Costs (25th, 75th } \\
\text { Percentile) (\$) }\end{array}$ & $\begin{array}{c}\text { In Catastrophic } \\
\text { Coverage Prior } \\
\text { to Index Date } \\
n(\%)\end{array}$ \\
\hline$\$ 0-\$ 25$ & 265 & $0 \quad(0.00)$ & 60.9 (13.1) & $46 \quad(17.4)$ & $198 \quad(74.7)$ & 127 (47.9) & 188 (70.9) & $\begin{array}{c}257.79 \\
(113.0,581.1)\end{array}$ & $48 \quad(18.1)$ \\
\hline$\$ 25-\$ 100$ & 21 & $1 \quad(4.76)$ & $66.2 \quad(10.4)$ & $1 \quad(4.8)$ & 17 (81.0) & 13 (61.9) & 12 (57.1) & $\begin{array}{c}1,285.58 \\
(662.01,3,479.52) \\
\end{array}$ & 13 (61.9) \\
\hline$\$ 100-\$ 250$ & 25 & $3(12.0)$ & $59.8 \quad(10.0)$ & $4(16.0)$ & $22(88.0)$ & $11(44.0)$ & $16(64.0)$ & $\begin{array}{c}288.92 \\
(148.43,504.99)\end{array}$ & $3(12.0)$ \\
\hline$\$ 250-\$ 400$ & 163 & 34 (20.9) & $64.9 \quad(8.4)$ & $41 \quad(25.2)$ & $128(78.5)$ & $53(32.5)$ & 100 (61.3) & $\begin{array}{c}472.50 \\
(255.00,746.46) \\
\end{array}$ & $4 \quad(2.5)$ \\
\hline$\$ 400-\$ 550$ & 225 & $65 \quad(28.9)$ & $65.5 \quad(9.4)$ & $72 \quad(32.0)$ & $177(78.7)$ & $85 \quad(37.8)$ & $144(64.0)$ & $\begin{array}{c}429.98 \\
(180.0,813.08) \\
\end{array}$ & $2 \quad(0.9)$ \\
\hline$>\$ 550$ & 165 & $54 \quad(32.7)$ & $63.8 \quad(10.5)$ & $31 \quad(18.8)$ & 129 & $68 \quad(41.2)$ & 112 (67.9) & $\begin{array}{c}798.99 \\
(407.82,1,587.43) \\
\end{array}$ & 17 (10.3) \\
\hline Overall & 864 & 157 (18.2) & $63.5 \quad(10.9)$ & 195 (22.6) & $671 \quad(77.7)$ & 357 (41.3) & $572(66.2)$ & $\begin{array}{c}440.56 \\
(188.66,877.29) \\
\end{array}$ & $87 \quad(10.1)$ \\
\hline
\end{tabular}

aP value for test for trend for members abandoning their prescription across cost groups $=<0.001$.

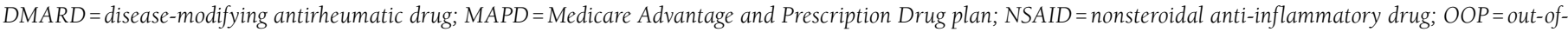
pocket; $R x=$ prescription; $S D=$ standard deviation

used to determine the factors associated with the likelihood of refilling a prescription for a biologic DMARD therapy. The generalized estimating equation (GEE) method was used with longitudinal panel data representing each Rx refill observation among members over time and time-dependent covariates whose values change over time. The advantage of utilizing generalized linear models and the GEE method for this type of analysis is that the model can account for correlations within subjects and include covariates of interest that change over time. Time-dependent covariates used for GEE model inclusion included previous refill count, OOP cost for the medication, pharmacy type (retail/specialty), catastrophic coverage threshold met $(\mathrm{Y} / \mathrm{N})$ at time of fill, yearly quarter of prescription fill, biologic DMARD therapy, and days supply of prescription fill.

The absence of biologic DMARD utilization data within the post-index period was assumed to indicate lack of utilization during this time frame and not missing data. Fixed covariates used for GEE model inclusion were age on index date; gender; ZIP code level median household income; ZIP code population percentage with high school diploma as highest attained level of education using ZIP code-level census data; race/ethnicity; history of DMARD use (Y/N) based on claims history during pre-period; history of NSAID use $(\mathrm{Y} / \mathrm{N})$ based on claims history during pre-period; urban versus rural residence; prescriber specialty; and baseline DCI.

The alpha level for all inferential analyses was set at 0.05, and all statistical tests were 2-tailed unless otherwise specified. Data were evaluated for violations of assumptions underlying the associated statistical tests as appropriate.

\section{Results}

For examination of prescription abandonment, there were 8,442 members who met the initial study criteria of being enrolled in a Medicare plan with both medical and prescription drug coverage and having a history of an adjudicated (paid or reversed) claim for a biologic DMARD indicated for RA from January 1, 2007, to December 31, 2012 (Figure 1). Requiring continuous enrollment in the health plan for 180 days prior to the index date and for 180 days following the index date dropped the qualified population to 4,777. After excluding for age and lack of a medical claim for RA during the study time period, the population was reduced to 3,209. Exclusion for enrollment in an employer-administered health plan group excluded from research, not having a paid claim for an RA medication during the study time period, enrollment in an LIS program, and eligibility for both Medicaid and Medicare coverage resulted in a final population of 864 MAPD members meeting the inclusion criteria.

Of the 864 members meeting the study criteria to evaluate the association between prescription abandonment rates of biologic DMARD therapies reimbursed through the pharmacy benefit and OOP member costs in members diagnosed with RA, the mean (standard deviation [SD]) age was 63.5 (10.9) years and the majority were female $(669,77.4 \%$, Table 1$)$. Across all cost groups, more than half lived in urban residence, and most (78\%) used conventional nonbiologic DMARDs in the study pre-period. Overall, the initial prescription abandonment rate was $18.2 \%$. As seen in Figure 3, the rate of prescription abandonment increased with the increase in OOP cost. In an unadjusted analysis, a test for trend revealed a significant 
TABLE 2 Assessment of the Association Between Prescription Abandonment and OOP Costs Among New Initiators of Biologic Therapy for RA in the MAPD Population

\begin{tabular}{|c|c|c|c|}
\hline & Odds Ratio & $95 \%$ CI & $P$ Value \\
\hline \multicolumn{4}{|l|}{ Rx OOP cost $(\$)$} \\
\hline$\$ 0-\$ 250.00$ (reference) & 1 & & \\
\hline$\$ 250.01-\$ 400.00$ & 18.42 & $(6.13-55.34)$ & $<0.001$ \\
\hline$\$ 400.01-\$ 550.00$ & 32.69 & $(11.23-95.13)$ & $<0.001$ \\
\hline$>\$ 550.00$ & 41.21 & $(14.00-121.32)$ & $<0.001$ \\
\hline \multicolumn{4}{|l|}{ Gender } \\
\hline Male & 1.07 & $(0.67-1.69)$ & 0.786 \\
\hline Age, years & 1.02 & $(1.00-1.04)$ & 0.133 \\
\hline \multicolumn{4}{|l|}{ Pharmacy type } \\
\hline Retail/other (reference) & 1 & & \\
\hline Specialty & 0.29 & $(0.15-0.56)$ & $<0.001$ \\
\hline $\begin{array}{l}\text { DMARD utilization } \\
\text { (No utilization reference) }\end{array}$ & 1.47 & $(0.88-2.46)$ & 0.140 \\
\hline $\begin{array}{l}\text { NSAID utilization } \\
\text { (No utilization reference) }\end{array}$ & 0.95 & $(0.63-1.45)$ & 0.819 \\
\hline \multicolumn{4}{|l|}{ Biologic on index date } \\
\hline Etanercept (reference) & 1 & & \\
\hline Adalimumab & 1.30 & $(0.85-1.99)$ & 0.222 \\
\hline Other & 3.79 & $(1.68-8.58)$ & 0.001 \\
\hline \multicolumn{4}{|l|}{ Prescriber specialty } \\
\hline Internal medicine (reference) & 1 & & \\
\hline Rheumatology & 1.49 & $(0.91-2.45)$ & 0.116 \\
\hline Other & 1.43 & $(0.86-2.38)$ & 0.174 \\
\hline \multicolumn{4}{|c|}{ Deyo Charlson Comorbidity Index } \\
\hline Score $=0$ (reference) & 1 & & \\
\hline Score $=1$ & 0.87 & $(0.45-1.66)$ & 0.664 \\
\hline Score $=2$ & 0.70 & $(0.32-1.56)$ & 0.389 \\
\hline Score $=3+$ & 0.94 & $(0.41-2.17)$ & 0.893 \\
\hline \multicolumn{4}{|c|}{ ZIP code-level median HH income } \\
\hline$<\$ 39,822.19$ (reference) & 1 & & \\
\hline$\$ 39,822.19-\$ 55,042.99$ & 0.96 & $(0.58-1.61)$ & 0.886 \\
\hline$>\$ 55,042.99$ & 1.00 & $(0.52-1.92)$ & 0.991 \\
\hline
\end{tabular}

ZIP code-level \% with HS education as highest attained level of education

\begin{tabular}{|c|c|c|c|}
\hline$<2.3 \%$ (reference) & 1 & & \\
\hline Quartile 2: $2.3 \%-35.5 \%$ & 3.06 & $(1.56-6.01)$ & 0.001 \\
\hline Quartile 3: 35.6\%-82.0\% & 2.79 & $(1.35-5.74)$ & 0.006 \\
\hline Quartile 4: $>82.0 \%$ & 3.38 & $(1.54-7.41)$ & 0.002 \\
\hline \multicolumn{4}{|l|}{ Residence } \\
\hline Urban (reference) & 1 & & \\
\hline Suburban & 0.64 & $(0.37-1.11)$ & 0.115 \\
\hline Rural/unknown & 0.95 & $(0.51-1.79)$ & 0.880 \\
\hline \multicolumn{4}{|c|}{ Total pre-period OOP health care costs (\$) } \\
\hline$<\$ 195.66$ (reference) & 1 & & \\
\hline$\$ 195.66-\$ 452.16$ & 2.12 & $(1.15-3.91)$ & 0.016 \\
\hline$\$ 452.16-\$ 889.85$ & 2.05 & $(1.10-3.83)$ & 0.024 \\
\hline$>\$ 889.85$ & 1.61 & $(0.84-3.07)$ & 0.151 \\
\hline $\begin{array}{l}\text { Catastrophic coverage limit } \\
\text { reached by index date }\end{array}$ & 0.14 & $(0.03-0.66)$ & 0.013 \\
\hline \multicolumn{4}{|l|}{ Race } \\
\hline White (reference) & 1 & & \\
\hline Black & 0.89 & $(0.46-1.72)$ & 0.721 \\
\hline Other & 1.00 & $(0.57-1.78)$ & 0.991 \\
\hline
\end{tabular}

$C I=$ confidence interval; DMARD = disease-modifying antirheumatic drug; $H H=$ household; HS = high school; $M A P D=$ Medicare Advantage and Prescription Drug plan; NSAID = nonsteroidal anti-inflammatory drug; OOP = out-of-pocket; $R A=$ rheumatoid arthritis; $R x=$ prescription . positive association between OOP cost and prescription abandonment rate for the study population $(P<0.001)$. A small portion of the population $(87,10.1 \%)$ was in catastrophic coverage during the study time period.

The likelihood of abandoning therapy was significantly increased for those with OOP expenses greater than $\$ 250$ per prescription relative to those with OOP expenses of $\$ 0-\$ 250$ (all, $P<0.001$; Table 2). Relative to etanercept, the likelihood of abandonment if the biologic received on the index date was a drug other than adalimumab was high (odds ratio $[\mathrm{OR}]=3.79$; $95 \%$ confidence interval $[\mathrm{CI}]=1.68-8.58 ; \mathrm{P}=0.001$ ). Also, pre-period OOP health care costs were associated with a greater likelihood of prescription abandonment. For example, the OOP cost range of $\$ 195.66-\$ 452.16$ relative to $<\$ 195.66$ yielded an OR of 2.12, with $P=0.016$, and for the OOP cost range of $\$ 452.16-\$ 889.85$ relative to $<\$ 195.66$ yielded an OR of 2.05 , with $P=0.024$. Meeting the catastrophic coverage limit by the index date and utilization of a specialty pharmacy for the index claim were both associated with a decreased likelihood of abandoning therapy (both, $P<0.05$ ).

A separate population and model were used to determine factors associated with the likelihood of refilling a biologic DMARD therapy indicated for the treatment of RA. As illustrated in Figure 2, 5,656 patients had a history of a paid claim for a biologic for RA for a 1-month supply of medication (28 to 31 days) during the study time period. After applying criteria for continuous enrollment, age, and having at least 1 medical claim associated with a diagnosis of RA during the 180 days prior to the index date or 30 days following the index date, 2,223 remained in the study. Further exclusion for enrollment included lack of a paid claim for RA during the study time period, enrollment in an LIS program, and eligibility for both Medicaid and Medicare coverage and resulted in the final cohort of 533 members.

The prospect of members refilling their prescriptions was lower for each OOP cost range examined (\$250.01-\$400.00, $\$ 400.01-\$ 550.00$, and $>\$ 550.00, P<0.001$; Table 3 ) and for members prescribed medication by a rheumatologist $(\mathrm{OR}=0.70 ; 95 \%$ $\mathrm{CI}=0.51-0.96)$. Relative to etanercept, the use of a medication other than adalimumab was also associated with decreased likelihood of refilling a prescription $(\mathrm{OR}=0.29 ; 95 \% \mathrm{CI}=0.16-0.53$; $P<0.001$ ), in addition to members residing in ZIP codes with $>60 \%$ of the population having high school as the highest attained level of education $(\mathrm{OR}=0.60 ; 95 \% \mathrm{CI}=0.38-0.93$; $P=0.023)$. However, the use of a specialty pharmacy suggested a greater likelihood of refilling a prescription $(\mathrm{OR}=1.36$; $95 \%$ $\mathrm{CI}=1.00-1.85 ; P=0.052$; Table 3).

\section{Discussion}

While there has been an increase in the availability of biologic DMARDs for the treatment of RA, this study found an overall abandonment rate of $18.2 \%$ for members initiating such 
Impact of Out-of-Pocket Costs on Prescription Fills Among New Initiators of Biologic Therapies for Rheumatoid Arthritis

TABLE 3 Factors Associated with the Likelihood of Refilling a Prescription for a Biologic Therapy Among Members with RA in the MAPD Population

\begin{tabular}{|c|c|c|c|c|c|c|c|}
\hline & Odds Ratio & $95 \%$ CI & $P$ Value & & Odds Ratio & $95 \% \mathrm{CI}$ & $P$ Value \\
\hline \multicolumn{4}{|l|}{ OOP cost $(\$)$} & \multicolumn{4}{|c|}{ ZIP code-level \% with HS education as highest attained level of education } \\
\hline$\$ 0-\$ 250.00$ (reference) & 1 & & & $<10 \%$ (reference) & 1 & & \\
\hline$\$ 250.01-\$ 400.00$ & 0.27 & $(0.17-0.42)$ & $<0.001$ & $10 \%-30 \%$ & 0.87 & $(0.56-1.37)$ & 0.552 \\
\hline$\$ 400.01-\$ 550.00$ & 0.27 & $(0.16-0.44)$ & $<0.001$ & $30 \%-60 \%$ & 0.66 & $(0.41-1.07)$ & 0.090 \\
\hline$>\$ 550.00$ & 0.27 & $(0.20-0.38)$ & $<0.001$ & $>60 \%$ & 0.60 & $(0.38-0.93)$ & 0.023 \\
\hline \multicolumn{4}{|l|}{ Gender } & \multicolumn{4}{|l|}{ Residence } \\
\hline Male (female reference) & 0.84 & $(0.61-1.15)$ & 0.276 & Urban (reference) & 1 & & \\
\hline Age, years & 1.01 & $(1.00-1.02)$ & 0.069 & Suburban & 0.97 & $(0.68-1.38)$ & 0.883 \\
\hline \multicolumn{4}{|l|}{ Pharmacy type } & Rural & 1.43 & $(0.89-2.30)$ & 0.138 \\
\hline Retail/other (reference) & 1 & & & Catastrophic coverage reached & 0.87 & $(0.51-1.46)$ & 0.592 \\
\hline Specialty & 1.36 & $(1.00-1.85)$ & 0.052 & by index date & & & \\
\hline DMARD utilization & 1.13 & $(0.81-1.57)$ & 0.463 & \multicolumn{4}{|c|}{ Total pre-period OOP health care costs (\$) } \\
\hline (No utilization reference) & & & & $\leq \$ 187.87$ (reference) & 1 & & \\
\hline \multirow{2}{*}{$\begin{array}{l}\text { NSAID utilization } \\
\text { (No utilization reference) }\end{array}$} & 1.13 & $(0.86-1.49)$ & 0.366 & $\$ 187.87-\$ 408.41$ & 1.04 & $(0.71-1.50)$ & 0.853 \\
\hline & & & & $\$ 408.41-\$ 816.11$ & 1.16 & $(0.77-1.74)$ & 0.481 \\
\hline \multicolumn{4}{|l|}{ Biologic brand } & $>\$ 816.11$ & 1.03 & $(0.70-1.52)$ & 0.884 \\
\hline Etanercept (reference) & 1 & & & Catastrophic coverage reached & 0.94 & $(0.66-1.34)$ & 0.735 \\
\hline Adalimumab & 0.82 & $(0.62-1.07)$ & 0.148 & at fill date & & & \\
\hline Other & 0.29 & $(0.16-0.53)$ & $<0.001$ & \multicolumn{4}{|l|}{ Race } \\
\hline \multicolumn{4}{|l|}{ Prescriber specialty } & White (reference) & 1 & & \\
\hline Internal medicine (reference) & 1 & & & Black & 0.82 & $(0.56-1.21)$ & 0.327 \\
\hline Rheumatology & 0.70 & $(0.51-0.96)$ & 0.029 & Other & 0.85 & $(0.59-1.22)$ & 0.378 \\
\hline Other & 0.80 & $(0.56-1.15)$ & 0.227 & \multicolumn{4}{|c|}{ Calendar yearly quarter of prescription fill } \\
\hline \multicolumn{4}{|c|}{ Deyo Charlson Comorbidity Index } & 1 (reference) & 1 & & \\
\hline Score $=0$ (reference) & 1 & & & 2 & 1.43 & $(0.96-2.14)$ & 0.080 \\
\hline Score $=1$ & 0.92 & $(0.57-1.49)$ & 0.747 & 3 & 1.13 & $(0.76-1.67)$ & 0.557 \\
\hline Score $=2$ & 0.97 & $(0.57-1.67)$ & 0.923 & 4 & 0.90 & $(0.61-1.35)$ & 0.624 \\
\hline Score $=3+$ & 0.96 & $(0.53-1.74)$ & 0.889 & \multicolumn{4}{|l|}{ Days supply of prescription fill } \\
\hline \multicolumn{4}{|c|}{ ZIP code-level median HH income } & 28-30 days (reference) & 1 & & \\
\hline$\leq \$ 38,028.43$ (reference) & 1 & & & $<28$ days & 0.57 & $(0.21-1.51)$ & 0.259 \\
\hline$\$ 38,028.43-\$ 49,534.68$ & 0.98 & $(0.70-1.38)$ & 0.909 & $>30$ days & 0.82 & $(0.19-3.54)$ & 0.798 \\
\hline$>\$ 49,534.68$ & 0.86 & $(0.56-1.32)$ & 0.485 & Previous refill count & 0.93 & $(0.83-1.04)$ & 0.188 \\
\hline
\end{tabular}

therapies. Furthermore, we observed a correlation between the member's OOP cost of the initial prescription and the likelihood the prescription would be abandoned: the higher the OOP cost, the greater the number of abandoned prescriptions. In the highest OOP cost group we examined (> \$550), the abandonment rate was $32.7 \%$ compared with the lowest OOP cost group (\$0-\$25), which had an abandonment rate of zero. A similar pattern has been observed in studies which examined RA prescription use. ${ }^{3,6,8,14,15}$ Gleason et al. (2009) ${ }^{9}$ found significantly higher abandonment rates at OOP costs of $\$ 101-\$ 150$ compared with cost of $\$ 100$ or less. Similar to what was observed in this study, for those with OOP costs greater than $\$ 500$, the abandonment rate was even higher. As shown elsewhere, the consequences of high cost-sharing may lead to therapy avoidance, which could result in greater overall health care costs due to disease-related complications..$^{8,16-19}$
Addressing the cost for treatment of diseases that require specialty medications can be challenging due to the ability or inability of members to fund their treatment to remain adherent. These studies suggest adherence may be improved by lowering the OOP cost for the member. Our main finding of increased abandonment as OOP costs rose is tempered by the fact that reaching the catastrophic threshold reduced abandonment (Table 2). While reducing member OOP cost may add to the short-term expense of the payer, the savings from preventing the consequences of members skipping doses may prove to be a financial benefit in terms of delay of disease progression and other consequences of advanced RA.

This concept is supported by the fact that lower abandonment rates were observed once members in the study reached the catastrophic coverage limit. In 2014, members reached the catastrophic coverage limit once they paid a cumulative $\$ 4,550$ 
OOP for covered drugs since the beginning of the year. After this point was reached, members were only required to pay a minimal fee for their prescriptions (either a $5 \%$ coinsurance for covered drugs or $\$ 2.55$ copay for covered generic drugs and $\$ 6.35$ for covered brand-name drugs, whichever was greater). ${ }^{20}$ As shown in Table 1, the majority of members who met the catastrophic coverage threshold by the index date were found in the lower OOP biologic DMARD cost groups. This finding implies that meeting the catastrophic coverage threshold is a means for lowering OOP biologic DMARD costs for members. The reduction in cost burden to the member appears to have a strong influence on members obtaining their medications. This behavior also emerged with the observation in this study that use of specialty pharmacy was correlated with reduced abandonment rates (Table 2). Specialty drug pharmacies often provide information to members related to their drug and disease state and around patient assistance programs. Added member communication and joint programs between manufacturers and payers to improve access may in turn improve adherence and downstream total health care costs.

In a similar pattern, higher prescription OOP costs correlated to lower odds of refilling a biologic DMARD prescription (Table 3). Interestingly, we note that the OR decreases with respect to OOP cost for pre-period health care and, in fact, at the highest-cost level, the OR is not significant ( $\$ 889.85$; $\mathrm{OR}=1.61 ; P=0.151$ ). This finding may be due to the fact that more members have reached the catastrophic coverage limit and is consistent with the finding in this study that reaching the catastrophic coverage threshold is associated with a lower likelihood of biologic DMARD prescription abandonment.

Surprisingly, members with rheumatologists as prescribers had significantly lower odds of refilling a prescription compared with members with internal medicine practitioners as prescribers. Further examining the member's relationship with the specific providers, the biologic DMARDs prescribed, and subsequent member behavior with regard to filling or abandoning specialty medications may help build an understanding that could drive changes to support enhanced adherence to these drugs.

\section{Limitations}

Limitations of this study include the 180-day washout period used to identify those newly initiating a biologic for RA, which may not have been long enough. Many members initially identified with RA were excluded from the analysis, since they had used biologic DMARDs indicated for RA in the 180 days prior to the index date, with the intention of limiting the study sample to members initiating biologic DMARD treatment. The inclusion of experienced users who had discontinued previously may have resulted in higher or lower refill rates based on the member's prior experience. For example, a member who discontinued in the past may have a higher likelihood of discontinuing again, or a member who is returning may acknowledge that his or her disease state needs to be managed, resulting in a higher rate of refills. It is unknown how the relationship between OOP costs and refills may have been altered as a result of the inclusion of such members.

Also, members receiving biologic DMARDs through the medical benefit portion of their health insurance plans were not included, since prescription reversals can only be tracked when the medication is processed through the pharmacy benefit. Other limitations common to studies using administrative claims data apply to this research, including lack of certain information in the database (e.g., lab results, weight, and health behavior information) and error in claims coding. No causal inference can be ascertained from this study, as it is an observational study using retrospective claims data. Although multivariate regression modeling was used in the present study to reduce selection bias and strengthen the causal inference, this approach can only reduce bias caused by measured covariates. It cannot reduce bias caused by unmeasured covariates. Because this study uses data from Humana members, the results may not be generalized to the general population. However, Humana is a large national health plan with members residing in a broad array of geographic regions.

\section{Conclusions}

According to the data obtained in this study, there is an unmet need for affordable biologic DMARDs in the Medicare population with RA. In this population, the lower the OOP cost, the more likely the member would remain adherent, while the higher the OOP cost, the less likely a member was to initiate therapy or follow through with refilling a prescription. Addressing this issue through reduction in OOP cost of the drugs would enable increased adherence in Medicare members with RA.

\section{Authors}

SARI HOPSON, MSPH, PhD, is Research Scientist; KIM SAVERNO, $P h D$, is Research Lead; MARY E. COSTANTINO, PhD, is Principal Science Writer; and MARGARET K. PASQUALE, PhD, is Research Manager, Comprehensive Health Insights, Louisville, Kentucky. JOHN ORAZEM, PhD, is Senior Director, Pfizer, New York, New York. LARRY Z. LIU, MD, PhD, was Senior Director and AHMAD AL-SABBAGH, MD, was Inflammation Biosimilars Global Medical Lead, Pfizer, New York, New York, at the time of this study.

AUTHOR CORRESPONDENCE: Margaret K. Pasquale, PhD, Comprehensive Health Insights, 515 W. Market St., Louisville, KY 40202. Tel.: 502.301.2747; Fax: 513.830.9180;

E-mail: mpasquale@humana.com. 


\section{DISCLOSURES}

This research project was funded jointly by Humana and Pfizer. The research concept was approved and plans to publish results were made known prior to commencing the study by the Joint Research Governance Committee of the Humana-Pfizer Research Collaboration, composed of Humana and Pfizer employees.

Hopson, Saverno, Costantino, and Pasquale are employees of Comprehensive Health Insights, a wholly owned subsidiary of Humana, who were paid consultants to Pfizer in connection with the development of this manuscript. Orazem is an employee of Pfizer. Liu and AL-Sabbagh were employees of Pfizer at the time of this study. Orazem, Liu, and AL-Sabbagh are stockholders of Pfizer.

An abstract of this study was presented as a podium presentation at the Academy of Managed Care 2014 Nexus, Boston, MA, October 7-10, 2014

Study design was created by Hopson, Saverno, Liu, and Pasquale. Hopson was responsible for data collection and analysis. Data interpretation was performed by Saverno, AL-Sabbagh, and Orazem, with assistance from the other authors. The manuscript was written primarily by Costantino, with assistance from Hopson, Pasquale, and Saverno, and revised by Costantino, Hopson, and Pasquale

\section{REFERENCES}

1. Sullivan SD. The promise of specialty pharmaceuticals: are they worth the price? J Manag Care Pharm. 2008;14(4 Suppl):S3-6. Available at: http://www. amcp.org/data/jmcp/JMCPSupp_S3-S6.pdf.

2. Desai RJ, Rao JK, Hansen RA, Fang G, Maciejewski ML, Farley JF. Predictors of treatment initiation with tumor necrosis factor- $\alpha$ inhibitors in patients with rheumatoid arthritis. J Manag Care Spec Pharm. 2014;20(11):1110-20. Available at: http://www.amcp.org/JMCP/2014/ November/18725/1033.html.

3. Gleason PP, Starner CI, Gunderson BW, Schafer JA, Sarran HS Association of prescription abandonment with cost share for high-cost specialty pharmacy medications. J Manag Care Pharm. 2009;15(8):648-58. Available at: http://www.amcp.org/data/jmcp/648-658.pdf.

4. Pasquale MK, Louder AM, Deminski MC, Chambers RB, Haider S. Outof-pocket costs and prescription reversals with oral linezolid. Am J Manag Care. 2013;19(9):734-40. Available at: http://www.ajmc.com/publications/ issue/2013/2013-1-vol19-n9/Out-of-Pocket-Costs-and-PrescriptionReversals-With-Oral-Linezolid/. Accessed November 17, 2015.

5. Dismuke CE, Egede LE. Medicare Part D prescription drug program: benefits, unintended consequences and impact on health disparities. J Gen Intern Med. 2013;28(7):860-61. Available at: http://link.springer.com/article/ 10.1007\%2Fs11606-013-2423-3. Accessed November 17, 2015.

6. Curkendall S, Patel V, Gleeson M, Campbell RS, Zagari M, Dubois R. Compliance with biologic therapies for rheumatoid arthritis: do patient out-ofpocket payments matter? Arthritis Rheum. 2008;59(10):1519-26. Available at: http://onlinelibrary.wiley.com/doi/10.1002/art.24114/abstract;jsessionid=8FF65 62D97E8F478BCDD9B0F5518DECF.f0lt02. Accessed November 17, 2015

7. Saag KG, Teng GG, Patkar NM, et al. American College of Rheumatology 2008 recommendations for the use of nonbiologic and biologic diseasemodifying antirheumatic drugs in rheumatoid arthritis. Arthritis Rheum. 2008;59(6):762-84. Available at: http://onlinelibrary.wiley.com/doi/10.1002/ art.23721/abstract. Accessed November 17, 2015
8. Karaca-Mandic P, Joyce GF, Goldman DP, Laouri M. Cost sharing, family health care burden, and the use of specialty drugs for rheumatoid arthritis. Health Serv Res. 2010;45(5 Pt 1):1227-50. Available at: http://onlinelibrary.wiley.com/doi/10.1111/j.1475-6773.2010.01117.x/abstract. Accessed November 17, 2015

9. Gleason PP, Alexander GC, Starner CI, et al. Health plan utilization and costs of specialty drugs within 4 chronic conditions. J Manag Care Pharm. 2013;19(7):542-48. Available at: http://www.amcp.org/JMCP/2013/ September_2013/17100/1033.html.

10. Fautrel B, Clarke AE, Guillemin F, et al. Costs of rheumatoid arthritis: new estimates from the human capital method and comparison to the willingness-to-pay method. Med Decis Making. 2007;27(2):138-50.

11. Bansback N, Marra CA, Finckh A, Anis A. The economics of treatment in early rheumatoid arthritis. Best Pract Res Clin Rheumatol. 2009;23(1):83-92.

12. Cardarelli WJ. Implications for managed care and specialty pharmacy in rheumatoid arthritis. Am J Manag Care. 2012;18(13 Suppl):S315-S24. Available at: http://www.ajmc.com/publications/supplement/2012/ ACE006_12dec_RA/ACE006_12dec_Cardarelli_S315to24/. Accessed November 17, 2015.

13. Pasma A, Van't Spijker A, Hazes JM, Busschbach JJ, Luime JJ. Factors associated with adherence to pharmaceutical treatment for rheumatoid arthritis patients: a systematic review. Semin Arthritis Rheum. 2013;43(1):18-28.

14. Schmajuk G, Trivedi AN, Solomon DH, et al. Receipt of diseasemodifying antirheumatic drugs among patients with rheumatoid arthritis in Medicare managed care plans. JAMA. 2011;305(5):480-86. Available at: http://jama.jamanetwork.com/article. aspx?articleid=645416. Accessed November 19, 2015

15. Solomon DH, Yelin E, Katz JN, Lu B, Shaykevich T, Ayanian JZ. Treatment of rheumatoid arthritis in the Medicare Current Beneficiary Survey. Arthritis Res Ther. 2013;15(2):R43-R43. Available at: http://arthritisresearch.com/content/15/2/R43. Accessed November 19, 2015.

16. Gibson TB, Ozminkowski RJ, Goetzel RZ. The effects of prescription drug cost sharing: a review of the evidence. Am J Manag Care. 2005;11(11):730-740 Available at: http://www.ajmc.com/publications/issue/2005/2005-11-voll1n11/Nov05-2205p730-740/. Accessed November 19, 2015.

17. Sokol MC, McGuigan KA, Verbrugge RR, Epstein RS. Impact of medication adherence on hospitalization risk and healthcare cost. Med Care. 2005;43(6):521-530.

18. Goldman DP, Joyce GF, Karaca-Mandic P. Varying pharmacy benefits with clinical status: the case of cholesterol-lowering therapy. Am J Manag Care. 2006;12(1):21-28. Available at: http://www.ajmc.com/publications/issue/ 2006/2006-01-voll2-nl/Jan06-2244p21-28/. Accessed November 19, 2015.

19. Thomson S, Schang L, Chernew ME. Value-based cost sharing in the United States and elsewhere can increase patients' use of high-value goods and services. Health Aff (Millwood). 2013;32(4):704-12.

20. Tsai AG, Williamson DF, Glick HA. Direct medical cost of overweight and obesity in the USA: a quantitative systematic review. Obes Rev. 2011;12(1):50-61. 